\title{
A propensity score-matched comparison between Cardia and Amplatzer PFO closure devices - insights from the SOLUTION registry (Swiss percutaneOus patent foramen ovale cLosUre in recurrent clinical events prevenTION)
}

Serban Puricel ${ }^{1}$, MD; Diego Arroyo ${ }^{1}$, MD; Jean-Jacques Goy ${ }^{1,2}$, MD; Fabien Praz ${ }^{3}, M D ;$ Nuno Palhais ${ }^{1}$, MD; Andreas Wahl ${ }^{3}$, MD; Jean-Christophe Stauffer ${ }^{1}, \mathrm{MD}$; Mario Togni ${ }^{1}$, MD; Alexandre Berger ${ }^{2}$, MD;

Bernhard Meier ${ }^{3}$, MD; Stéphane Cook ${ }^{1 *}$, MD

1. The University Hospital Fribourg, Fribourg, Switzerland; 2. The Cecil Clinic, Lausanne, Switzerland; 3. The University Hospital Bern, Bern, Switzerland

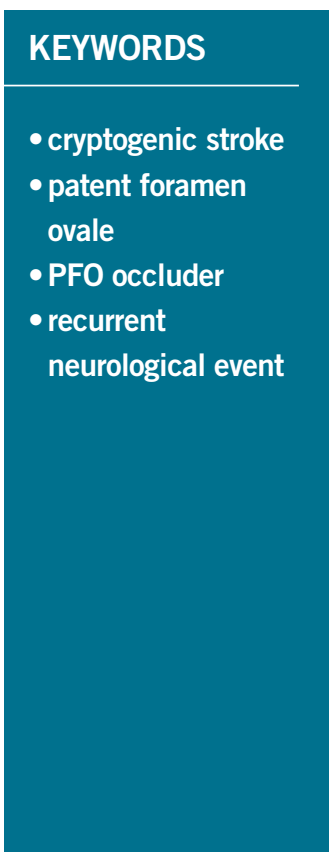

\section{Abstract}

Aims: To compare clinical outcome of Amplatzer PFO (APFO) to Cardia PFO (CPFO) occluder. Percutaneous patent foramen ovale (PFO) closure prevents stroke recurrence in stroke due to paradoxical embolism.

Methods and results: The primary endpoint was a composite of stroke, TIA, or peripheral embolism at follow-up. The secondary endpoint was residual shunt. Outcome was compared among 934 (APFO: 712; CPFO: 222) patients, and in 297 propensity score-matched patients. The primary endpoint occurred in 29 patients ( $0.71 / 100$ patient-years): four ( $2 \%)$ with the $\mathrm{CPFO}(0.31 / 100$ patient-years), and $25(4 \%)$ with the APFO (0.89/100 patient-years) $(\mathrm{p}=0.20)$. Residual shunt at six months was more frequent with the CPFO $(31 \%$ versus $9 \%, \mathrm{p}<0.001)$. No differences in residual shunts were seen at the last available echocardiographic follow-up ( $9 \pm 18$ months): APFO 11\%, CPFO 14\%, $\mathrm{p}=0.22$.

Conclusions: This study suggests that $\mathrm{PFO}$ closure with APFO or CPFO is equally effective for the prevention of recurrent events. Residual shunt was more frequent at six months with CPFO, but was similar to APFO at later follow-up.

\footnotetext{
*Corresponding author: Department of Cardiology, Hospital and University of Fribourg, Chemin des Pensionnats 2-6, 1708
} Fribourg, Switzerland.E-mail: stephane.cook@unifr.ch 


\section{Abbreviations}

$\begin{array}{ll}\text { APFO } & \text { Amplatzer PFO occluder } \\ \text { ASA } & \text { atrial septal aneurysm } \\ \text { CPFO } & \text { Cardia PFO occluder } \\ \text { CS } & \text { cryptogenic stroke } \\ \text { PFO } & \text { patent foramen ovale } \\ \text { PS } & \text { propensity score } \\ \text { RNE } & \text { recurrent neurological events } \\ \text { TEE } & \text { transoesophageal echocardiography } \\ \text { TIA } & \text { transient ischaemic attack } \\ \text { TTE } & \text { transthoracic echocardiography }\end{array}$

\section{Introduction}

Nearly 610,000 people experience a stroke each year in the United States $^{1}$, while the annual incidence in Europe is approximately 139 per 100,000 inhabitants ${ }^{2}$. Patent foramen ovale (PFO) is the most common cardiac congenital anatomical variant present on autopsy and is found in up to $25 \%$ of the population ${ }^{3,4}$. In 1877 Cohnheim suggested an association between PFO and cryptogenic stroke $(\mathrm{CS})^{5}$. Lechat et al reiterated this concept in $1988^{6}$. Since then, numerous reports have confirmed the role of PFO in the genesis of paradoxical embolism ${ }^{7-9}$. The annual risk attributed to paradoxical embolism has been estimated at 28 per 100,000 persons with $\mathrm{PFO}^{10}$. Mechanical percutaneous PFO closure has been developed amongst other therapeutic modalities. The first percutaneous PFO closure was described by Bridges in $1992^{11}$. Since then, it has evolved into a manifoldly employed therapeutic modality for patients in whom stroke was presumably due to a paradoxical embolism.

The risk of recurrent stroke is three times higher in patients who present a PFO as compared to those who do not ${ }^{12}$ and encourages prophylactic treatment. Whether mechanical closure is superior to medical treatment is still debated, but the results of the latest randomised controlled RESPECT trial suggest mechanical closure to be significantly superior to medical therapy in preventing recurrent stroke ${ }^{13}$. The randomised controlled CLOSURE I trial failed to demonstrate superiority of PFO closure plus medical therapy over best medical therapy ${ }^{14}$. On the other hand, propensity score-matched long-term analysis ${ }^{13}$ and a recent meta-analysis ${ }^{14}$ comparing PFO closure with medical therapy showed mechanical closure superior to medical management. The latter calculated recurrent neurological events as $0.4-0.8$ events per 100 person-years (95\% CI: 0.5-1.1) for transcatheter closure versus 2.5-5.0 events per 100 person-years (95\% CI: 3.6-6.9) for medical treatment. Considering the limited number of studies comparing the various PFO occluders $^{15-20}$, we aimed to compare the clinical outcomes of patients after implantation of either the Amplatzer PFO occluder (APFO; St. Jude Medical, St. Paul, MN, USA) or the Cardia Intrasept occluder (CPFO; Cardia Inc., Eagan, MN, USA) in a large population of unselected consecutive patients.

\section{Methods}

\section{PATIENTS, DEFINITIONS AND INITIAL WORK-UP}

From January 2000 to February 2011, all consecutive patients over 18 years of age undergoing percutaneous PFO closure with either
$\mathrm{APFO}$ or CPFO in two different Swiss hospitals were prospectively included in the SOLUTION registry. Indications included ischaemic stroke, transient ischaemic attack (TIA), disabling migraine, decompression illness (DCI), and peripheral embolism. Stroke and TIA were defined according to the World Health Organization (WHO). Stroke was a sudden new neurological deficit lasting $>24$ hours. TIA was considered as a neurological dysfunction lasting $<24$ hours $^{21}$. Neurologists of the local institutions made the distinction between complex migraine and TIA. Diagnostic criteria for such events were the same across the different institutions as they are harmonised in Switzerland according to the international guidelines. Both centres adhered to these diagnostic criteria.

Additional evaluation and considerations were as follows:

- Stroke and TIA were presumably related to PFO if a complete work-up for other possible aetiologies was negative. This workup included brain imaging (computed tomography or magnetic resonance), Doppler and colour duplex examination of the carotid and vertebral arteries and blood testing.

- Disabling migraine headache required confirmation by a neurologist and other causes of headache had to be excluded before the patient could be considered for inclusion in the registry.

- Decompression sicknesses were classified according to Bühlmann $^{22}$.

- Peripheral embolism was considered related to PFO when other possible cardiac sources were excluded.

The presence of PFO was confirmed by colloid bubble contrast transoesophageal echocardiography (TEE) or transthoracic echocardiography (TTE). A PFO was considered as any shunt through a septum primum and secundum gap assessed by either TTE or TEE and visualisation through the interatrial crossing of aerated colloid solution injected into the antecubital or femoral vein at the end of a strenuous and sustained Valsalva manoeuvre. Atrial septal aneurysm (ASA) was diagnosed using the same imaging modalities and was defined as a redundant and mobile interatrial septum with a minimum 10 to $15 \mathrm{~mm}$ excursion during the cardiorespiratory cycle ${ }^{23}$.

\section{INCLUSION AND EXCLUSION CRITERIA}

Inclusion criteria in the registry further required successful percutaneous PFO closure with one of the studied devices, a signed written informed consent and willingness to participate in long-term follow-up. Patients intolerant to antiplatelet agents or anticoagulants were excluded. This study was approved by all local ethics committees and complied with the Declaration of Helsinki.

\section{STUDY DEVICES, PROCEDURES AND TREATMENT ASSIGNMENT}

Four devices divided into two groups were used in this study. The Amplatzer PFO occluder (AGA Medical Corp., Golden Valley, MN, USA) and three Cardia devices (Cardia Inc., Eagan, MN, USA): the PFO-Star, the Intrasept and the Atriasept occluders. Cardia devices were used in a sequential order: from 2000 to 2002 the PFO-Star was implanted, from 2002 until March 2008 the Intrasept occluder was implanted and finally from March 2008 until the end of the study 
period the Atriasept occluder was implanted. All operators were well trained in PFO closure. PFO closure using APFO was exclusively performed under local anaesthesia and fluoroscopic guidance. PFO closure using CPFO was usually performed under general anaesthesia with TEE and fluoroscopic guidance. TTE was performed within 24 hours to confirm correct and stable device position. All patients received dual antiplatelet therapy (acetylsalicylic acid $100 \mathrm{mg} / \mathrm{d}$ and clopidogrel $75 \mathrm{mg} / \mathrm{d}$ ) for one to six months.

The device used depended on physician preferences in each centre: all patients treated at Bern University Hospital received an Amplatzer PFO occluder, whereas patients treated in Lausanne were implanted with one of the studied Cardia devices. Device choice in the different institutions was solely motivated by local policies and preferences.

\section{DATA COLLECTION AND FOLLOW-UP}

All patients were actively followed with regard to recurrence of the initial clinical event that led to study inclusion or to clinical events attributable to PFO. Follow-up data were obtained through clinic visits or phone calls. The last available follow-up was considered as maximum follow-up. For suspected or reported adverse events all relevant medical documents were retrieved from one of the abovementioned sources. The local event adjudication committee reviewed each event.

Follow-up contrast echocardiography was performed in all patients at one and six months. After six months, subsequent echocardiographic examinations were left at the discretion of the referring cardiologist.

\section{STUDY ENDPOINTS}

The pre-specified primary endpoint was a composite of stroke, TIA, or peripheral embolism within the maximum follow-up period. In patients with multiple events, the first event was considered achievement of the study endpoint. The secondary endpoint was residual shunt at six months and at the latest echocardiographic testing assessed by contrast echocardiography. Bleeding complications were classified according to the Bleeding Academic Research Consortium $^{24}$.

\section{STATISTICAL ANALYSIS}

Analyses were performed using SPSS software version 18.0 (SPSS Inc., Chicago, IL, USA). Continuous variables are expressed as mean \pm standard deviation or median with interquartile range. Categorical variables are expressed as counts and percentages. For continuous variables Q-Q plots were computed and the KolmogorovSmirnov test was employed to check for a normal distribution. We compared baseline characteristics between patients treated with APFO and CPFO using a chi-square test for categorical variables, an unpaired t-test for continuous variables with a normal distribution and non-parametric tests such as the Wilcoxon rank sum test for continuous variables with a non-Gaussian distribution. We then used propensity score (PS) matched analysis to account for differences in baseline characteristics. PS for receiving APFO was estimated using a logit model including age, gender, and pretreatment variables associated with device selection in the multivariable model at $\mathrm{p}<0.10$ as independent variables (hypercholesterolaemia, left ventricular ejection fraction [LVEF] and PFO with concomitant ASA). The multivariable model was computed (AUC $=0.80$, good discrimination) using the forward stepwise selection. Greedy matching in the form of nearest neighbour matching within a caliper of \pm 0.05 (corresponding in this case to a quarter of the SD of the PS which was 0.19 ) on the propensity score was employed and randomly matched one patient treated with CPFO to two patients treated with APFO. Only patients with cerebrovascular events were eligible for the matching procedure and were matched according to event type, i.e., stroke or TIA. Univariate and multivariate analysis was then performed on the matched sample, the dependent variable being treatment status, in order to account for equity in visible covariates and thus an ignorable treatment assignment. As the survival functions of the matched sample did not meet the proportionality assumption required to perform a Cox proportional hazard regression, we computed odds ratios for the endpoints. Odds ratios for the entire study population were derived using univariable binary logistic regression. Odds ratios for the matched sample were derived using conditional binary logistic regression. Propensity score matching was only used for the analysis of residual shunt at six months and at latest follow-up. Kaplan-Meier curves were truncated at nine years.

\section{Results}

\section{BASELINE PATIENT CHARACTERISTICS}

The final sample consisted of 934 patients: 712 patients in the APFO group, and 222 in the CPFO group. Within the CPFO group, $36(16 \%)$ patients received a PFO-Star, $130(59 \%)$ the Intrasept occluder, and 56 (25\%) the Atriasept PFO occluder.

Patient demographics are summarised in Table 1. The overall 934-patient population had a mean age of $51.3 \pm 4.9$ years and a majority of men $(58 \%, \mathrm{n}=542)$. Arterial hypertension, smoking, and hypercholesterolaemia were present in $31 \%(\mathrm{n}=285), 31 \%$ $(n=286)$, and $42 \%(n=390)$, respectively. The prevalence of diabetes was $4 \%(n=35)$. Nearly half of the patients presented a concomitant ASA $(48 \%, n=444)$. Ischaemic stroke and/or TIA accounted for $88 \%(\mathrm{n}=818)$ of PFO closures.

The APFO group contained more male ( $60 \%$ vs. $52 \%, \mathrm{p}=0.03)$, hypercholesterolaemic patients ( $45 \%$ vs. $32 \%$, p=0.001) with a better LVEF (65\% vs. $64 \%$, p $<0.001)$ and fewer ASA (39\% vs. 75\%, $\mathrm{p}<0.001)$ than the CPFO group. The indication for PFO closure varied widely and marginal indications were more frequent in the CPFO group.

The 2:1 (two APFO for one CPFO patient) matching of patients with cerebrovascular events based on the predicted probabilities on the propensity score was able to segregate a total of 297 patients, of whom 198 belonged to the APFO and 99 to the CPFO group. No significant differences with regard to visible covariates remained after the matching procedure (Table 1). In binary logistic regression, no variable independently predicted treatment assignment. 
Table 1. Baseline patient characteristics before and after propensity score matching.

\begin{tabular}{|c|c|c|c|c|c|c|c|c|}
\hline & \multicolumn{4}{|c|}{ Before propensity score* matching } & \multicolumn{4}{|c|}{ After propensity score* matching } \\
\hline & $\begin{array}{c}\text { APFO } \\
(\mathrm{N}=712)\end{array}$ & $\begin{array}{c}\text { CPFO } \\
(\mathrm{N}=222)\end{array}$ & $\begin{array}{c}\text { Standardised } \\
\text { difference }\end{array}$ & p-value & $\begin{array}{c}\text { APFO } \\
(N=198)\end{array}$ & $\begin{array}{c}\text { CPFO } \\
(\mathrm{N}=99)\end{array}$ & $\begin{array}{c}\text { Standardised } \\
\text { difference }\end{array}$ & $p$-value \\
\hline Age, years $\pm S D$ & $51 \pm 13$ & $51 \pm 13$ & 0.04 & 0.73 & $53 \pm 12$ & $53 \pm 13$ & -0.02 & 0.85 \\
\hline Male, n (\%) & $427(60)$ & $115(52)$ & 0.17 & 0.03 & $94(48)$ & $46(47)$ & 0.02 & 0.87 \\
\hline Weight, $\mathrm{kg} \pm \mathrm{SD}$ & $76 \pm 16$ & $74 \pm 16$ & 0.14 & 0.02 & $75 \pm 18$ & $73 \pm 15$ & 0.11 & 0.52 \\
\hline Height, metre \pm SD & $1.72 \pm 0.09$ & $1.71 \pm 0.09$ & 0.09 & 0.13 & $1.71 \pm 0.09$ & $1.71 \pm 0.09$ & 0.01 & 0.65 \\
\hline $\mathrm{BMI}, \mathrm{m}^{2} \pm \mathrm{SD}$ & $25.6 \pm 4.4$ & $24.9 \pm 4.5$ & 0.16 & 0.61 & $25.4 \pm 4.9$ & $24.6 \pm 4.7$ & 0.13 & 0.42 \\
\hline Hypertension, n (\%) & $226(32)$ & $59(27)$ & 0.11 & 0.15 & $58(29)$ & $28(28)$ & 0.02 & 0.86 \\
\hline Diabetes, $\mathrm{n}(\%)$ & $31(4)$ & $4(2)$ & 0.15 & 0.08 & $5(3)$ & $1(1)$ & 0.11 & 0.38 \\
\hline Smoker, n (\%) & $225(32)$ & $61(28)$ & 0.09 & 0.25 & $56(28)$ & 29 (29) & -0.02 & 0.86 \\
\hline Dyslipidaemia, n (\%) & $318(45)$ & $72(32)$ & 0.25 & 0.001 & $70(35)$ & $29(29)$ & 0.13 & 0.3 \\
\hline Indication & & & & 0.001 & & & & 1.0 \\
\hline TIA, n (\%) & 263 (37) & $83(37)$ & -0.01 & 0.96 & $116(59)$ & $58(59)$ & 0 & 1.0 \\
\hline Stroke, n (\%) & $402(56)$ & $65(29)$ & 0.57 & $<0.0001$ & $82(41)$ & $41(41)$ & 0 & 1.0 \\
\hline Stroke and TIA, n (\%) & $0(0)$ & $5(2)$ & -0.02 & 0.005 & $0(0)$ & $0(0)$ & - & - \\
\hline Migraine, $\mathrm{n}(\%)$ & $1(0)$ & $13(6)$ & -0.34 & $<0.0001$ & $0(0)$ & $0(0)$ & - & - \\
\hline $\mathrm{DCl}, \mathrm{n}(\%)$ & $0(0)$ & $16(8)$ & -0.39 & $<0.0001$ & $0(0)$ & $0(0)$ & - & - \\
\hline Peripheral embolism, n (\%) & $44(6)$ & $2(1)$ & 0.29 & 0.003 & $0(0)$ & $0(0)$ & - & - \\
\hline Platypnoea-orthodeoxia, n (\%) & $0(0)$ & $5(2)$ & -0.21 & 0.0005 & $0(0)$ & $0(0)$ & - & - \\
\hline Other, n (\%) & $2(0)$ & $33(15)$ & -0.57 & $<0.0001$ & $0(0)$ & $0(0)$ & - & - \\
\hline $\mathrm{LA}>40 \mathrm{~mm}, \mathrm{n}(\%)$ & $142(20)$ & $33(15)$ & 0.13 & 0.84 & $42(21)$ & $27(27)$ & -0.14 & 0.49 \\
\hline LVEF, \% [IQR] & 65 [65-65] & $64[60-65]$ & 0.35 & $<0.001$ & $65[60-65]$ & $65[60-65]$ & -0.04 & 0.27 \\
\hline PFO + ASA, n (\%) & 277 (39) & $167(75)$ & -0.79 & $<0.001$ & $154(78)$ & $80(81)$ & -0.07 & 0.55 \\
\hline
\end{tabular}

*The model for propensity score computation included the following variables: age, gender, dyslipidaemia, LVEF, PFO+ASA, stroke. ASA: atrial septal aneurysm; DCI: decompression illness; IQR: interquartile range; kg: kilogram; LA: left atrium; LVEF: left ventricular ejection fraction; m: metre;

PFO: patent foramen ovale; SD: standard deviation; TIA: transient ischaemic attack

The multivariate model used to calculate the propensity score is displayed in Table 2.

\section{IMPLANTATION AND PROCEDURE-RELATED COMPLICATIONS}

There was no device malfunction. Ninety-nine percent of the procedures were event-free and most were performed on an out-patient basis. Overall, procedure-related complications occurred in 10 cases (1\%): six (1\%) belonged to the APFO and four $(2 \%)$ to the CPFO group $(\mathrm{p}=0.27)$. Complications in the APFO group were as follows:

Table 2. Multivariate model used for propensity score calculation.

\begin{tabular}{|l|c|c|c|c|}
\hline \multirow{2}{*}{ Significance } & \multirow{2}{*}{ Odds ratio } & \multicolumn{2}{|c|}{ 95\% CI } \\
\cline { 4 - 5 } & & & Lower limit & Upper limit \\
\hline Gender & 0.140 & 1.349 & 0.906 & 2.009 \\
\hline Dyslipidaemia & 0.003 & 1.922 & 1.254 & 2.945 \\
\hline LVEF & $<0.001$ & 1.096 & 1.052 & 1.142 \\
\hline PF0 with ASA & $<0.001$ & 0.159 & 0.102 & 0.249 \\
\hline Age & 0.429 & 1.006 & 0.991 & 1.022 \\
\hline Stroke & $<0.001$ & 2.785 & 1.844 & 4.207 \\
\hline $\begin{array}{l}\text { ASA: atrial septal aneurysm; LVEF: left ventricular ejection fraction; PF0: patent foramen } \\
\text { ovale }\end{array}$
\end{tabular}

AV fistula $(n=5)$ and branch occlusion of the right retinal artery $(n=1)$. Complications in the CPFO group were as follows: atrial fibrillation and transient ST elevation presumably due to a gas embolism $(n=1)$, transient right leg paresis $(n=1)$, postoperative minor bleeding at the puncture site $(n=1)$, and periprocedural catheter thrombosis $(n=1)$.

Of the five $(2 \%)$ complications remaining after PS matching, three $(2 \%)$ occurred in patients treated with APFO and two $(2 \%)$ in those treated with CPFO $(\mathrm{p}=0.89)$.

\section{RESIDUAL SHUNT AT SIX-MONTH ECHOCARDIOGRAPHIC FOLLOW-UP}

Follow-up echocardiography was available in 873 patients (93\%). It consisted of a TEE with APFO and a TTE with CPFO. Time to echocardiography was 6.2 (IQR 5.2-7.2) months and did slightly differ between the two groups (APFO 6.3 [5.9-7.2] months vs. CPFO 6.1 [2.8-7.3] months, $\mathrm{p}=0.005)$. The difference persisted although less significantly in the matched sample (APFO 6.1 [5.67.1] months vs. CPFO 6.0 [3.4-6.9] months, $\mathrm{p}=0.04$ ).

At six-month follow-up, residual shunt was present in 131 patients (14\%). There was a statistically significant difference between both groups with 62 patients (9\%) in the APFO group and 
69 patients $(31 \%)$ in the CPFO group $(\mathrm{p}<0.001)$. The three different CPFO had similar residual shunts with $31 \%(\mathrm{p}<0.001)$ for the PFOStar, 32\% $(p<0.001)$ for the Intrasept and $32 \%(p<0.001)$ for the Atriasept.

Binary logistic regression of the complete study population showed that treatment with APFO (OR 0.2, 95\% CI: 0.12-0.33, $\mathrm{p}<0.001)$ inferred a significant decrease in odds for PFO patency at six months. Furthermore, male gender (OR 1.76, 95\% CI: $1.03-$ 2.99, $\mathrm{p}=0.04$ ) and a PFO with concomitant ASA (OR 1.94, 95\% CI: $1.2-3.13, \mathrm{p}<0.01)$ significantly increased the odds of a residual shunt at six-month follow-up (Figure 1).

Other variables considered in the model were age (OR 0.99, 95\% CI: 0.97-1.01, p=0.39), body weight (per additional $\mathrm{kg}$ ) (OR 1.01, 95\% CI: 0.99-1.03, p=0.08), LVEF (OR 0.97, 95\% CI: 0.93-1.01, $\mathrm{p}=0.18$ ), dyslipidaemia (OR 1.39, 95\% CI: 0.87-2.2, $\mathrm{p}=0.16$ ), and stroke as indication for PFO closure (OR 1.23, 95\% CI: 0.78-1.94, $\mathrm{p}=0.38$ ) as well as TIA and stroke (OR 0.66, 95\% CI: 0.06-7.79, $\mathrm{p}=0.75$ ).

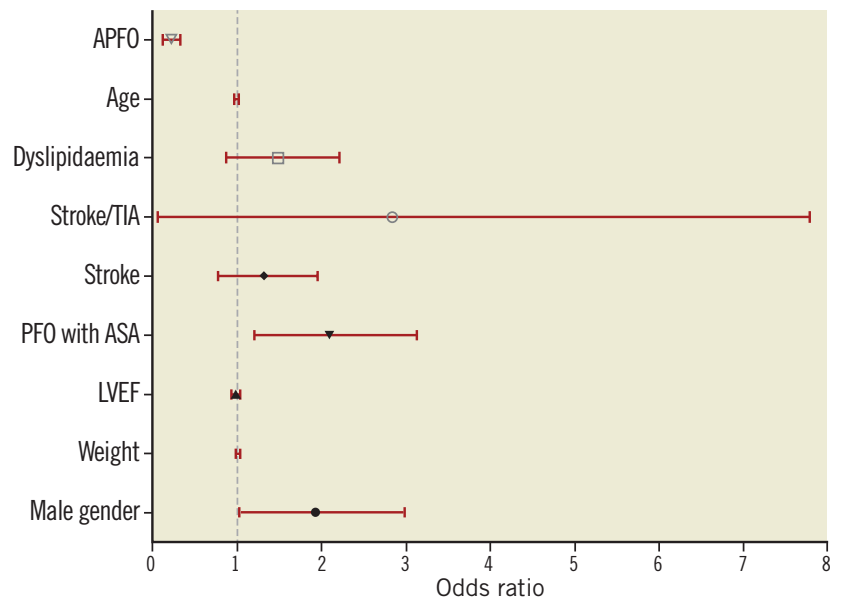

Figure 1. Multivariate model for the prediction of residual shunt at six-month follow-up (entire study population). APFO: Amplatzer PFO occluder; ASA: atrial septal aneurysm; LVEF: left ventricular ejection fraction; PFO: patent foramen ovale; TIA: transient ischaemic attack
In the matched population, residual shunt was detected in 52 patients (18\%). Again, the APFO group showed a significantly lower rate of residual shunt when compared to CPFO patients $(11 \%$ $[n=21]$ vs. $31 \%[n=31], p<0.001)$. Figure 2 depicts the performance of the APFO compared to the CPFO.

\section{FOLLOW-UP AND CLINICAL ENDPOINTS}

Follow-up was available in all patients $(100 \%)$ with a mean duration of $4.4 \pm 2.7$ years (range 0.5-11.5 years) and differed significantly, being longer in CPFO patients with a mean duration of $5.8 \pm 2.9$ years when compared to APFO patients who were followed for a mean of $3.9 \pm 2.5$ years $(\mathrm{p}<0.001)$.

Table 3 summarises clinical follow-up. There were no significant differences regarding clinical outcome. At maximal follow-up, the primary composite endpoint occurred in 29 patients $(0.71 / 100$ patient-years): four $(2 \%)$ in the CPFO group $(0.31 / 100$ patientyears) and 25 (4\%) in the APFO group (0.89/100 patient-years) $(\mathrm{p}=0.20)$. Overall, recurrences occurred with a median time of 1.8 years (IQR 0.5-4.3 years). They occurred somewhat earlier in CPFO patients (1.5 years [IQR 0.3-7.3 years]) when compared to the APFO patients (2.0 years [IQR 0.5-4.3 years]) but this was not statistically significant $(\mathrm{p}=0.78)$. Figure 2 depicts the Kaplan-Meier

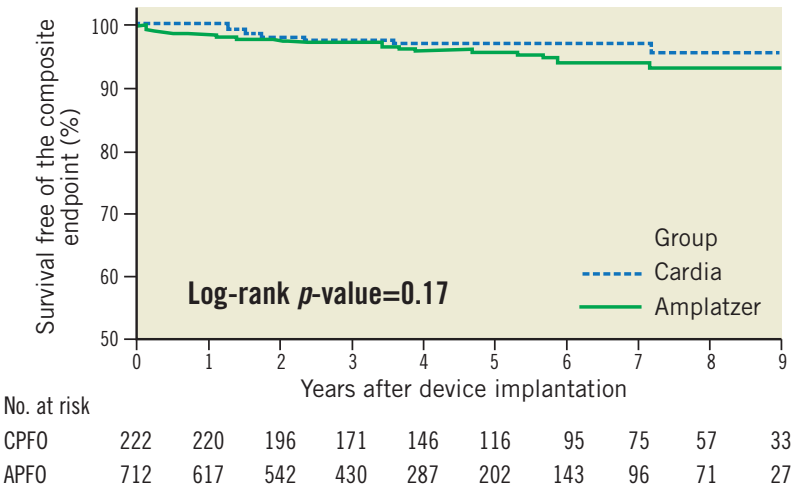

Figure 2. Kaplan-Meier estimate for survival free of recurrence or death in the entire cohort at nine-year follow-up. APFO: Amplatzer PFO occluder; CPFO: Cardia PFO occluder

Table 3. Study endpoints before and after propensity score matching.

\begin{tabular}{|c|c|c|c|c|c|c|c|c|c|c|}
\hline & \multicolumn{5}{|c|}{ Before propensity score matching } & \multicolumn{5}{|c|}{ After propensity score matching } \\
\hline & $\begin{array}{c}\text { Overall } \\
(\mathrm{N}=934)\end{array}$ & $\begin{array}{c}\text { APFO } \\
(n=712)\end{array}$ & $\begin{array}{c}\text { CPFO } \\
(n=222)\end{array}$ & $\begin{array}{c}\text { OR } \\
(95 \% \text { CI) }\end{array}$ & $p$-value ${ }^{*}$ & $\begin{array}{l}\text { Overall } \\
(\mathrm{N}=297)\end{array}$ & $\begin{array}{c}\text { APFO } \\
(n=198)\end{array}$ & $\begin{array}{c}\text { CPFO } \\
(n=99)\end{array}$ & $\begin{array}{c}\text { OR } \\
(95 \% \text { CI) }\end{array}$ & $p$-value \\
\hline Death, n (\%) & $8(1)$ & $4(1)$ & $4(2)$ & $0.31(0.08-1.24)$ & 0.11 & & & & & \\
\hline Recurrence (\%) & $29(3)$ & $25(4)$ & $4(2)$ & $1.98(0.68-5.77)$ & 0.2 & & & & & \\
\hline $\begin{array}{l}\text { Residual shunt at } \\
6 \text { months, } n(\%)\end{array}$ & $131(14)$ & $62(9)$ & $69(31)$ & $0.22(0.15-0.33)$ & $<0.001$ & $52(18)$ & $21(11)$ & $31(31)$ & $0.24(0.12-0.48)$ & $<0.001$ \\
\hline $\begin{array}{l}\text { Residual shunt at last } \\
\text { echocardiography, } n(\%)\end{array}$ & $86(9)$ & $62(9)$ & 24/186 (13) & $0.74(0.44-1.23)$ & 0.24 & $52(18)$ & $21(11)$ & $12 / 85(14)$ & $0.67(0.3-1.5)$ & 0.32 \\
\hline Composite endpoint, $n(\%)$ & $36(4)$ & $28(4)$ & $8(4)$ & $1.16(0.5-2.72)$ & 0.83 & & & & & \\
\hline
\end{tabular}


curve for survival free of the primary composite endpoint. Death was encountered in eight patients ( $1 \%-0.14 / 100$ patient-years): four $(2 \%)$ in the CPFO group $(0.31 / 100$ patient-years) and four $(1 \%)$ in the APFO group $(0.14 / 100$ patient-years) $(p=0.17)$. Causes of death were as follows: generalised cancer (two), chronic kidney failure (one), stroke recurrence (one), dive accident in spite of hyperoxaemia due to a defective oxygen valve (one), car accident (one), multi-organ failure caused by a septic shock (one), and death of unknown cause (one).

Furthermore, of the 14 patients in whom the indication for PFO closure was migraine, six patients (43\%) reported a complete disappearance of their headache, six patients (43\%) reported a decrease in its frequency and two patients (14\%) did not notice any modification of their migraine at all.

In the overall patient population, $53 \%$ of patients $(n=496$, $\mathrm{APFO}=57 \%$ vs. $\mathrm{CPFO}=41 \% ; \mathrm{p}<0.001)$ were still on aspirin, $100 \mathrm{mg} / \mathrm{d}$, at maximum follow-up. In the matched sample, the patients still on aspirin, $100 \mathrm{mg} / \mathrm{d}$ at maximum follow-up, represented 54\% $(\mathrm{n}=160 ; \mathrm{APFO}=56 \%$ vs. $\mathrm{CPFO}=51 \% ; \mathrm{p}=0.62)$. Whether aspirin was continued or not had no significant impact on the clinical outcome, as 14 out of 29 (in the overall sample; $p=0.58$ ) and two out of six (in the matched sample; $\mathrm{p}=0.42$ ) patients who achieved the primary endpoint were still taking the drug daily at maximum follow-up.

In the matched population, patients were followed for a mean of $4.4 \pm 2.8$ years. The follow-up duration for CPFO was significantly longer (6.1 \pm 2.8 years) than for APFO $(3.5 \pm 2.4$ years; $\mathrm{p}<0.001)$.

\section{RESIDUAL SHUNT AT LONGER FOLLOW-UP}

No significant differences in residual shunts were reported at the last available echocardiographies ( $9 \pm 18$ months): $11 \%$ for the APFO group versus $14 \%$ for the CPFO group, $\mathrm{p}=0.32$. The delay to echocardiography only changed for patients in the CPFO group, whereas it stayed the same for patients in the APFO group.

\section{Discussion}

The present prospective registry with medium-term clinical outcome has the following main findings:

- Percutaneous PFO closure is safe with high success and low complication rates.

- Recurrent stroke, TIA or peripheral embolism has an annual incidence under $1 \%$.

- Although residual shunts were initially more frequent with $\mathrm{CPFO}$ compared to APFO, both devices were equally effective for medium-term recurrent event prevention.

- Similarly, no differences in echocardiographic permeability remained during the extended follow-up.

\section{RECURRENT NEUROLOGICAL EVENTS (RNE) AFTER PFO CLOSURE}

The main interest of each PFO occluder must be its propensity to reduce RNEs. Accordingly, the strength of our data is the high number of patients, the extended follow-up (up to 11 years), and the non-selection of patients, reflecting real-life daily practice. We demonstrated that yearly RNE recurrence rate is below $1 \%$. This is in accordance with previous reported incidences in registries ${ }^{15,20,25}$ and a randomised trial ${ }^{14}$. These results underscore that percutaneous PFO closure is a safe procedure with a good medium-term outcome. Given that observational studies and meta-analyses on medical treatment report higher annual RNE rates (ranging from 3.8\% to $12 \%)^{26-29}$, the present study insinuates that PFO occlusion is superior to medical therapy. This is consistent with a recent PS-matched comparison of percutaneous PFO closure with medical treatment where PFO closure was indeed shown to be more effective than medical treatment ${ }^{13}$. Prospective randomised studies with longterm follow-up are still missing but a longer follow-up from the CLOSURE I trial, and results from the RESPECT and the PC trial are eagerly awaited.

\section{DEVICE COMPARISON}

Both devices had a $100 \%$ procedural success rate, while in the CLOSURE I trial the procedural success was $90 \%$. Device selection might have had an impact on the procedure and clinical outcome. Thrombus formation, for example, was found more frequently with the STARFlex closure device used in the CLOSURE I trial ${ }^{14}$ than in the present study.

To date, data are scarce regarding device comparison. The heterogeneous inclusion and follow-up duration preclude any formal conclusion ${ }^{14-16,18,19}$. Some studies have consecutively enrolled patients, which may lead to operator-driven device selection and bias $^{18}$. In the present registry we aimed to compare APFO to CPFO in a large consecutively enrolled patient population with an extended clinical follow-up. No differences in procedural complications were seen. We found that six-month residual shunt was more frequent in the CPFO group than the APFO group. However, these differences disappeared at longer echocardiographic followup and one could therefore consider that septum healing after APFO implantation is quicker but similar to CPFO. Again, there were no outcome differences regarding stroke recurrence, TIA or peripheral embolism.

\section{LIMITATIONS}

The main limitation of the present study is its non-randomised design and comparison of the two devices used at two different centres. PS matching allowed an appropriate comparison between patients; however, given that the inclusion criteria were physician and patient-based, selection bias may have occurred.

Another main limitation is the fact that multivariable adjustment for the primary composite endpoint in the entire study population was not feasible due to a lack of statistical power. The results given are of univariate nature and thus likely confounded.

A further limitation is the use of TTE for follow-up in the CPFO group. TTE has a lower sensitivity for small residual shunts than TEE. The residual shunt rate difference reported in favour of the APFO is therefore likely to be underestimated. This may also explain the difference between this report and a previous one 
comparing the same device families ${ }^{21}$. Last, we must also acknowledge the lack of neuroradiological data as being another limitation of this article.

\section{Impact on daily practice}

Due to its invasive nature, percutaneous PFO closure has been debated since its inception. The current data show, however, that percutaneous PFO closure is safe, with high success and low complication rates. In daily practice, the interventional community should keep in mind that recurrent ischaemic events are kept to a minimum after PFO closure with an annual incidence $<1 \%$, and that both Amplatzer and Cardia devices perform equally in preventing them.

\section{Funding}

This work was supported by the "Fonds Scientifique cardiovasculaire" (Fribourg, Switzerland).

\section{Conflict of interest statement}

B. Meier is a consultant for St. Jude Medical. J-J. Goy and J-C. Stauffer are consultants for Cardia. The other authors have no conflicts of interest to declare.

\section{References}

1. Roger VL, Go AS, Lloyd-Jones DM, Adams RJ, Berry JD, Brown TM, Carnethon MR, Dai S, de Simone G, Ford ES, Fox CS, Fullerton HJ, Gillespie C, Greenlund KJ, Hailpern SM, Heit JA, Ho PM, Howard VJ, Kissela BM, Kittner SJ, Lackland DT, Lichtman JH, Lisabeth LD, Makuc DM, Marcus GM, Marelli A, Matchar DB, McDermott MM, Meigs JB, Moy CS, Mozaffarian D, Mussolino ME, Nichol G, Paynter NP, Rosamond WD, Sorlie PD, Stafford RS, Turan TN, Turner MB, Wong ND, Wylie-Rosett J; American Heart Association Statistics Committee and Stroke Statistics Subcommittee. Heart disease and stroke statistics - 2011 update: a report from the American Heart Association. Circulation. 2011;123:e18-e209.

2. Alzamora MT, Sorribes M, Heras A, Vila N, Vicheto M, Fores R, Sanchez-Ojanguren J, Sancho A, Pera G. Ischemic stroke incidence in Santa Coloma de Gramenet (ISISCOG), Spain. A community-based study. BMC Neurol. 2008;8:5.

3. Meier B, Frank B, Wahl A, Diener HC. Secondary stroke prevention: patent foramen ovale, aortic plaque, and carotid stenosis. Eur Heart J. 2012;33:705-13, 713a, 713b.

4. Hagen PT, Scholz DG, Edwards WD. Incidence and size of patent foramen ovale during the first 10 decades of life: an autopsy study of 965 normal hearts. Mayo Clin Proc. 1984;59:17-20.

5. Cohnheim J. Thrombose und Embolie. In: Vorlesungen über Allgemeine Pathologie. Berlin, Germany: Hirschwald; 1877;1:134.

6. Lechat P, Mas JL, Lascault G, Loron P, Theard M, Klimczac M, Drobinski G, Thomas D, Grosgogeat Y. Prevalence of patent foramen ovale in patients with stroke. $N$ Engl $J$ Med. 1988;318:1148-52.
7. Sacco RL, Ellenberg JH, Mohr JP, Tatemichi TK, Hier DB, Price TR, Wolf PA. Infarcts of undetermined cause: the NINCDS Stroke Data Bank. Ann Neurol. 1989;25:382-90.

8. Petty GW, Khandheria BK, Chu CP, Sicks JD, Whisnant JP. Patent foramen ovale in patients with cerebral infarction. A transesophageal echocardiographic study. Arch Neurol. 1997;54: 819-22.

9. Handke M, Harloff A, Olschewski M, Hetzel A, Geibel A. Patent foramen ovale and cryptogenic stroke in older patients. N Engl J Med. 2007;357:2262-8.

10. Kraywinkel K, Jauss M, Diener HC, Weimar C. [Patent foramen ovale, atrial septum aneurysm, and stroke. An examination of the status of recent evidence]. Nervenarzt. 2005;76:935-42.

11. Bridges ND, Hellenbrand W, Latson L, Filiano J, Newburger JW, Lock JE. Transcatheter closure of patent foramen ovale after presumed paradoxical embolism. Circulation. 1992;86:1902-8.

12. Agarwal S, Bajaj NS, Kumbhani DJ, Tuzcu EM, Kapadia SR. Meta-analysis of transcatheter closure versus medical therapy for patent foramen ovale in prevention of recurrent neurological events after presumed paradoxical embolism. JACC Cardiovasc Interv. 2012;5:777-89.

13. Carroll JD, Saver JL, Thaler DE, Smalling RW, Berry S, MacDonald LA, Marks DS, Tirschwell DL; RESPECT Investigators. Closure of patent foramen ovale versus medical therapy after cryptogenic stroke. N Engl J Med. 2013;368:1092-100.

14. Furlan AJ, Reisman M, Massaro J, Mauri L, Adams H, Albers GW, Felberg R, Herrmann H, Kar S, Landzberg M, Raizner A, Wechsler L; CLOSURE I Investigators. Closure or medical therapy for cryptogenic stroke with patent foramen ovale. N Engl J Med. 2012;366:991-9.

15. Meier JM, Berger A, Delabays A, Girod G, Graf D, Lyon X, Roguelov C, Vogt P, Stauffer JC, Eeckhout E. Percutaneous closure of patent foramen ovale: head-to-head comparison of two different devices. EuroIntervention. 2005;1:48-52.

16. Spies C, Reissmann U, Timmermanns I, Schrader R. Comparison of contemporary devices used for transcatheter patent foramen ovale closure. J Invasive Cardiol. 2008;20:442-7.

17. Herrmann HC, Silvestry FE, Glaser R, See V, Kasner S, Bradbury D, Chang G, Hirshfeld JW Jr, Horwitz PA, Kelly M. Percutaneous patent foramen ovale and atrial septal defect closure in adults: results and device comparison in 100 consecutive implants at a single center. Catheter Cardiovasc Interv. 2005;64:197-203.

18. Thaman R, Faganello G, Gimeno JR, Szantho GV, Nelson M, Curtis S, Martin RP, Turner MS. Efficacy of percutaneous closure of patent foramen ovale: comparison among three commonly used occluders. Heart. 2011;97:394-9.

19. Taaffe M, Fischer E, Baranowski A, Majunke N, Heinisch C, Leetz M, Hein R, Bayard Y, Buscheck F, Reschke M, Hoffmann I, Wunderlich N, Wilson N, Sievert H. Comparison of three patent foramen ovale closure devices in a randomized trial (Amplatzer versus CardioSEAL-STARflex versus Helex occluder). Am J Cardiol. 2008;101:1353-8. 
20. Braun M, Gliech V, Boscheri A, Schoen S, Gahn G, Reichmann H, Haass M, Schraeder R, Strasser RH. Transcatheter closure of patent foramen ovale (PFO) in patients with paradoxical embolism. Periprocedural safety and mid-term follow-up results of three different device occluder systems. Eur Heart J. 2004;25:424-30.

21. Stroke--1989. Recommendations on stroke prevention, diagnosis, and therapy. Report of the WHO Task Force on Stroke and other Cerebrovascular Disorders. Stroke. 1989;20:1407-31.

22. Bühlmann AA. Decompression-Decompression Sickness. Berlin New York: Springer-Verlag. 1984 (ISBN 0-38713308-9).

23. Mas JL, Arquizan C, Lamy C, Zuber M, Cabanes L, Derumeaux G, Coste J; Patent Foramen Ovale and Atrial Septal Aneurysm Study Group. Recurrent cerebrovascular events associated with patent foramen ovale, atrial septal aneurysm, or both. N Engl J Med. 2001;345:1740-6.

24. Mehran R, Rao SV, Bhatt DL, Gibson CM, Caixeta A, Eikelboom J, Kaul S, Wiviott SD, Menon V, Nikolsky E, Serebruany V, Valgimigli M, Vranckx P, Taggart D, Sabik JF, Cutlip DE, Krucoff MW, Ohman EM, Steg PG, White H. Standardized bleeding definitions for cardiovascular clinical trials: a consensus report from the Bleeding Academic Research Consortium. Circulation. 2011;123:2736-47.
25. Wahl A, Jüni P, Mono ML, Kalesan B, Praz F, Geister L, Raber L, Nedeltchev K, Mattle HP, Windecker S, Meier B. Longterm propensity score-matched comparison of percutaneous closure of patent foramen ovale with medical treatment after paradoxical embolism. Circulation. 2012;125:803-12.

26. Messe SR, Silverman IE, Kizer JR, Homma S, Zahn C, Gronseth G, Kasner SE; Quality Standards Subcommittee of the American Academy of Neurology. Practice parameter: recurrent stroke with patent foramen ovale and atrial septal aneurysm: report of the Quality Standards Subcommittee of the American Academy of Neurology. Neurology. 2004;62:1042-50.

27. Bogousslavsky J, Garazi S, Jeanrenaud X, Aebischer N, Van Melle G. Stroke recurrence in patients with patent foramen ovale: the Lausanne Study. Lausanne Stroke with Paradoxal Embolism Study Group. Neurology. 1996;46:1301-5.

28. Mohr JP, Thompson JL, Lazar RM, Levin B, Sacco RL, Furie KL, Kistler JP, Albers GW, Pettigrew LC, Adams HP Jr, Jackson CM, Pullicino P; Warfarin-Aspirin Recurrent Stroke Study Group. A comparison of warfarin and aspirin for the prevention of recurrent ischemic stroke. N Engl J Med. 2001;345:1444-51.

29. Khairy P, O'Donnell CP, Landzberg MJ. Transcatheter closure versus medical therapy of patent foramen ovale and presumed paradoxical thromboemboli: a systematic review. Ann Intern Med. 2003;139:753-60. 